\title{
The Analysis of the Studies on Non-Routine Problems
}

\author{
Sibel KAYA ${ }^{1}$, Zeynel KABLAN ${ }^{2}$ \\ ${ }^{1}$ Kocaeli University, Faculty of Education, Kocaeli, Turkey, sibelkaya@gmail.com \\ https://orcid.org/0000-0001-8417-3627 \\ ${ }^{2}$ Kocaeli University, Faculty of Education, Kocaeli, Turkey, zeynelkablan@gmail.com \\ https://orcid.org/0000-0003-2338-5516
}

Received : 24.10.2017

Accepted : 10.05.2018

Doi: $10.17522 /$ balikesirnef.437652

\begin{abstract}
A number of studies examined non-routine questions in mathematics learning in recent years. The purpose of this study is to examine the studies on non-routine problems in the national and international literature. In doing so, the study designs, methods and results were described. Among the descriptive analysis techniques, document analysis was used in the study. A total of 60 descriptive and experimental studies on nonroutine problems were compiled using various databases. Four research questions guided the analysis of the studies. One of the main findings was that the participants in the studies were more successful in solving nonroutine questions compared to routine questions. Moreover, the participants were not successful in utilizing more than one solutions for non-routine questions. It is believed that proving students with problem solving and metacognitive learning strategies would increase their achievement in non-routine problems. Conducting further studies on the effects of different instructional approaches and techniques on non-routine problem solving is recommended.
\end{abstract}

Key words: Non-routine problems, descriptive analysis, document analysis, experimental and descriptive studies, mathematics

Corresponding Author: Sibel KAYA, Kocaeli University

\section{Summary}

Programme of International Student Assessment (PISA) mainly tests student achievement on non-routine problems in various fields (OECD, 2014). Similarly, in Trends in Mathematics and Science Study (TIMSS), the complete section of reasoning is composed of non-routine questions (Kolovou, van den Heuvel-Panhuizen, \& Bakker, 2009). When student achievement on non-routine problems increases, their overall achievement also increases (Altun \& Memnun, 2008; Çelebioğlu, Yazgan \& Ezentaş, 2010; De Hoys, Gray \& Simpson, 2004). 
Routine questions can easily be found in textbooks and they consist of basic computations and definitions (Santos-Trigo, \& Camacho-Machín, 2009). The main purpose of asking routine questions is to improve students' basic problem solving skills and to rehearse definitions (Ulu, 2008). Non-routine problems on the other hand, cannot easily be found in textbooks. These questions are unfamiliar to students and they require advanced skills to solve. Students need to use their prior knowledge and experiences to solve a new problem (Kolovou et al., 2009; Schoenfeld, 1999).

Previous studies showed that there is a positive correlation between solving non-routine problems and student achievement (Altun \& Memnun, 2008; Çelebioğlu, Yazgan \& Ezentaş, 2010; De Hoys, Gray\& Simpson, 2004). Non-routine questions not only improve students's problem solving skills but also their attitudes towards problem solving (Altun \& Memnun, 2008). Pourdavood (2012) found that when non-routine questions are used in classrooms, students tend to be more attentive and excited; they discuss solutions and they question other ideas.

In recent years, number of descriptive, correlational and experimental studies examined non-routine questions in mathematics learning. Some of these studies examined problem solving strategies used by students (Arslan \& Yazgan, 2015; Artut \& Tarım, 2006, 2009; Bayazit, 2013; Chacko, 2004; Muir, Beswick \& Williamson, 2008), while others used the effects of different strategies and techniques on non-routine problem solving (Altun \& Memnun, 2008; Ebret, 2015; Kurbal, 2015; Taylor \& McDonald, 2007; Verschaffel \& De Corte, 1997; Yazgan \& Bintaş, 2005). The purpose of this study is to systematically examine the studies on non-routine problems in the national and international literature.

\section{Method}

Among the descriptive analyses techniques, document analysis was used in the study. A total of 60 studies published between 1994 and 2016 were compiled using various databases. The studies used descriptive, correlational or experimental design on non-routine problems. The study designs, methods and results of those studies were descriptively examined. The studies were coded in Excel using pre-determined categories. Frequencies and percentages were reported. Four research questions guided the analysis of the studies. Accordingly, the distribution of studies based on study design, data collection instruments and sampling; and the results of experimental, descriptive and correlational studies were reported separately.

\section{Findings}


Based on study design, nearly half of the studies were descriptive and the other half was divided between correlational and experimental studies. Almost $80 \%$ of the studies were conducted with students. The studies overwhelmingly used achievement tests and some of them used surveys.

Among the experimental studies, the most frequently used independent variables were problem solving strategy and metacognitive strategy. Both of these strategies were successful in improving students' non-routine problem solving skills. Among the descriptive studies, the most frequently examined variable was problem solving strategies used by students when solving non-routine problems. It was reported that students solve non-routine problems as if they are routine and they have difficulty in transferring their everyday knowledge to the solutions of non-routine problems. The correlational studies examined the relationships between non-routine problem solving skills and a number of variables, such as gender, grade level, attitudes towards problem solving, problem solving self-efficacy, parental role and receiving early childhood education. Since there were only one or two studies regarding each variable, it is difficult to make and generalizations.

\section{Discussion and Conclusion}

One of the main findings was that the participants in the studies were more successful in solving non-routine questions compared to routine questions. Since routine questions are much more common in both tests and textbooks (Artut \& Tarım, 2006, 2009; İncebacak \& Ersoy, 2016), it is inevitable for students to be more successful on routine questions compared to non-routine ones.

The participants were not successful in utilizing more than one solutions for non-routine questions. They have difficulties in using multiple strategies and their everyday experiences when solving problems, providing informal and original solutions to non-routine problems. It is believed that proving students with problem solving and metacognitive learning strategies would increase their achievement in non-routine problems. Metacognition refers to awareness and understanding of one's own thinking and learning processes (Karakelle \& Saraç, 2010). Knowing about their own strengths and weaknesses and criticizing their way of thinking help students become more successful in problem solving. Conducting further studies on the effects of different instructional approaches and techniques on non-routine problem solving is recommended. 


\title{
Rutin Olmayan Problemlerle İlgili Yapılan Araştırmaların Analizi
}

\author{
Sibel KAYA ${ }^{1}$, Zeynel KABLAN ${ }^{2}$ \\ ${ }^{1}$ Kocaeli Üniversitesi, Eğitim Fakültesi, Kocaeli, Türkiye, sibelkaya@gmail.com \\ https://orcid.org/0000-0001-8417-3627 \\ ${ }^{2}$ Kocaeli Üniversitesi, Eğitim Fakültesi, Kocaeli, Türkiye, zeynelkablan@gmail.com \\ https://orcid.org/0000-0003-2338-5516
}

Makale Gönderme Tarihi: 24.10.2017

Makale Kabul Tarihi: 10.05 .2018

\section{Doi: $10.17522 /$ balikesirnef.437652}

Özet - Son yıllarda rutin olmayan problemleri, özellikle matematik alanında, çeşitli yönleriyle inceleyen araştırmalar mevcuttur. Bu çalışmanın amacı ise rutin olmayan problemlerle ilgili yapılmış ulusal ve uluslararası alanyazındaki araştırmaları çeşitli değişkenler açısından incelemektir. İlgili araştırmalar incelenirken temel olarak kullanılan araştırma deseni, yöntemi gibi süreçler ve bu süreçlere dayalı olarak elde edilen sonuçlar betimlenmeye çalışılmıştır. $\mathrm{Bu}$ çalışmada betimsel analiz yöntemlerinden doküman inceleme yöntemi kullanılmıştır. Araştırmada analiz edilmek üzere kapsama dahil edilen çalışmalar, rutin olmayan problem çözme ile ilgili deneysel ve betimsel araştırmalardan oluşmaktadır. Araştırma örneklemine dahil edilen toplam 60 adet çalışmanın analiz edilmesinde 4 soru kullanılmıştır. Bu araştırmada sonuç olarak, incelenen araştırmalara katılan öğrencilerin genel olarak problemi birden fazla strateji24.10.2017 kullanarak çözme konusunda yeterli olmadıkları ve rutin soruları rutin olmayanlara göre daha kolay çözebildikleri görülmüştür. Öğrencilere problem çözme ve üst bilişsel öğrenme stratejileri gibi becerilerin kazandırılmasının başarılarını arttırabilir. Diğer taraftan, çeşitli öğretim yaklaşım, yöntem ve tekniklerin rutin olmayan problem çözmeye etkisini belirlemeyi amaç edinecek daha fazla araştırmaya ihtiyaç duyduğu söylenebilir.

Anahtar kelimeler: Rutin olmayan problemler, betimsel analiz, doküman inceleme, deneysel ve betimsel araştırmalar, matematik

Sorumlu Yazar: Sibel KAYA, Kocaeli Üniversitesi

\section{Giriş}

Son yıllarda yapılan uluslararası değerlendirme araştırmalarında öğrencilerin rutin olmayan, günlük yaşam problemlerinde gösterdikleri performans ilgili ülkeler açısından büyük önem arzetmektedir (Kolovou, van den Heuvel-Panhuizen, \& Bakker, 2009; OECD, 2014). Bu sınavlarda öğrencilerin rutin olmayan problemleri çözme becerisi arttıkça genel başarı düzeyleri de artmaktadır (Altun ve Memnun, 2008; Çelebioğlu, Yazgan ve Ezentaş, 2010; De Hoys, Gray \& Simpson, 2004). Rutin olmayan problemler, rutin problemlerin 
aksine öğrencilerin aşina olmadığ 1 soru türleridir ve rutin soruların çözümüne kıyasla daha fazla bilişsel çaba gerektirir (Mullis ve ark., 2003).

Rutin problemler ders kitaplarında sıklıkla karşılaşılan, temel işlemler ve tanımları içeren sorulardır (Santos-Trigo, \& Camacho-Machín, 2009). Bu tür problemler genel olarak, öğrencilerin temel işlem becerilerini geliştirmek ve yazılı ve görsel metinleri anlamalarına yardımcı olmak amacıyla kullanılır (Ulu, 2008). Rutin olmayan problemler ise kitaplarda sıklıkla karşılaşılmayan ve öğrencilerin ön bilgilerini yeni bir duruma uyarlamaları gereken problem durumlarını içerir (Kolovou ve ark., 2009; Schoenfeld, 1999). Rutin problemlerin çözümünde işlem becerisi ve ezber yeterli olurken, rutin olmayan problemlerin çözümünde verileri düzenleme, hipotez kurma, yorum yapma gibi üst düzey bilimsel süreç becerilerine ihtiyaç vardır (Jurdak, 2005; Lee, Yeo \& Hong, 2014; Nancarrow, 2004). Polya'ya göre, problem çözmeye yönelik bazı prosedürlerin ve tanımların öğrenilebilmesi için rutin soruların kullanılması gereklidir; ancak, öğrencilerin problem çözme becerilerini gerçek anlamda geliştiren sorular rutin olmayan sorulardır (Polya, 1962).

Öğrenciler derslerde genellikle tek bir çözüm yolu olan rutin sorulara maruz kalmaktadırlar (Artut ve Tarım, 2006, 2009; İncebacak \& Ersoy, 2016; Kaya, Kablan \& Rice, 2014; Kolovou ve ark., 2009; Marchis, 2012; Özmen, Taşkın ve Güven, 2012; Teong ve ark., 2009). Dolayısıyla, öğrenciler bu tür sorularda daha başarılı olmaktadırlar (Artut ve Tarım, 2006, 2009; İncebacak \& Ersoy, 2016). Rutin soruların çözümünün öğretilmesi fazla zaman ve çaba gerektirmemektedir (Silver, Ghousseini, Gosen, Charalambous \& Strawhun, 2005). Genel olarak öğretmenin gösterdiği veya ders kitabında verilen yöntemi kullanarak öğrenciler kolayca çözüme ulaşabilmektedir (Harskamp \& Suhre, 2007). Fakat bu, onların problem çözme becerilerine sahip olduğu anlamına gelmemektedir (Silver ve ark., 2005). Öğrenciler zaman zaman, bilgi ve becerilerini uygulamalarını gerektiren yeni bir durumla karşılaştıklarında güçlük çekebilmektedirler. Dolayısıyla, öğrencileri sık sık aşina olmadıkları yeni problemlerle karşı karşıya bırakmak onların akıl yürütme becerilerini kullanarak farklı çözüm yolları üretmelerine yardımcı olacaktır (English \& Halford, 1995; Stein, Grover \& Henningsen, 1996).

Rutin olmayan problemler öğrencilerin akıl yürütme ve problem çözme becerisini geliştirdiği gibi onların problem çözmeye yönelik bakış açılarını da değiştirir (Altun ve Memnun, 2008). Sinıflarda rutin olmayan problemler sorulduğunda öğrencilerin daha ilgili ve heyecanlı oldukları ve tartışmalara daha çok katıldıkları gözlenmiştir. Derslerde yaşanan 
olumlu deneyimler öğrencilerin günlük hayatta karşılaştırkları problemleri çözme konusunda onları motive edecektir (Pourdavood, 2012).

Ancak, öğretmenler, rutin olmayan soruların gerektirdiği öğretim yükü ile başa çıkmak istemediklerinden, bu sorulara sınıflarında fazla yer vermemektedirler (Silver ve ark., 2005). Aşina olmayan problemlerin sunulması, çözümün planlanması, çözüm için gerekli bilgi ve becerilerin tartışılması gibi uygulamalara sınıflarda yer verilmemektedir (Teong ve ark., 2009). Öğretmenler rutin olmayan sorulara öğrencilerin düşünme becerilerini geliştirmesi açısından olumlu baksalar da sınavlarda sorulmaması gerektiğini savunmaktadır (Asman \& Markovitz, 2009). Öğretmenlerin bu tutum ve davranışlarından dolayı, öğrenciler aşina olmayan bir problemle karşılaştıklarında anlama güçlüğü çekmekte ve başarısız olmaktadırlar (Teong ve ark., 2009). Araştırmacılara göre, öğrencilerin problem çözmedeki başarısızlıkları bilgi eksikliğinden değil, daha çok bilgiyi nasıl kullanacaklarını bilmemelerinden kaynaklanmaktadır (Schoenfeld, 1987; Van Streum, 2000).

Son yıllarda rutin olmayan problemleri, özellikle matematik alanında, çeşitli yönleriyle inceleyen araştırmalar mevcuttur. $\mathrm{Bu}$ araştırmalardan bir kısmı, rutin olmayan problem çözmedeki başarının (Çelik ve Güler, 2013; Dündar, 2015) ve rutin olmayan problem çözerken kullanılan stratejilerin incelendiği (Arslan ve Yazgan, 2015; Artut ve Tarım, 2006, 2009; Bayazit, 2013; Chacko, 2004; Muir, Beswick \& Williamson, 2008) basit betimsel türde araştırmalar olduğu gibi; çeşitli değişkenlerin rutin olmayan problem çözme ile ilişkisinin incelendiği (Callejo \& Vila, 2009; Elia, van den Heuvel-Panhuizen \& Kolovou, 2009; Pantziara, Gagatsis \& Iliada, 2009; Taşkın, Aydın, Akşan ve Güven, 2012; Yıldırım ve Ersözlü, 2013) korelasyonel araştırmalar olarak karşımıza çıkmaktadır. Ayrıca, literatürde çeşitli eğitim, yöntem ve tekniklerin rutin olmayan problem çözmeye etkisinin incelendiği (Altun ve Memnun, 2008; Arslan ve Altun, 2007; Ebret, 2015; Kurbal, 2015; Taylor \& McDonald, 2007; Verschaffel \& De Corte, 1997; Yazgan ve Bintaş, 2005) deneysel araştırmalar da bulunmaktadır.

$\mathrm{Bu}$ çalışmanın amacı rutin olmayan problemlerle ilgili yapılmış ulusal ve uluslararası alanyazındaki araştırmaları çeşitli değişkenler açısından incelemektir. İlgili araştırmalar incelenirken temel olarak, kullanılan araştırma yöntemleri, veri toplama araçları, örneklem türleri, değişkenleri ve elde edilen sonuçları betimlenmeye çalışılmıştır. Bu amaçla elde edilen sonuçların bundan sonraki dönemlerde bu alanda yapılacak yeni araştırmalara yön vermesi beklenmektedir.

\section{Yöntem}


$\mathrm{Bu}$ çalışmada betimsel analiz yöntemlerinden doküman inceleme yöntemi kullanılmıştır. Doküman incelemesi, araştırılması hedeflenen olgular hakkında bilgi içeren sözlü, basılı vb. materyallerden tek tek elde edilen verilerin bir araya getirilmesi ile genellemelere ve yorumlara ulaşmayı kapsar (Yıldırım ve Şimşek, 2016).

\section{Araştırma Kapsamı}

Araştırmada analiz edilmek üzere kapsama dahil edilen çalışmalar, rutin olmayan problem çözme ile ilgili deneysel ve betimsel araştırmalardan oluşmaktadır. Çalışma kapsamında en son araştırmaya 01 Nisan 2017 tarihinde ulaşılmıştır. Hangi araştırmaların analize dahil edileceğine yönelik seçimlerin yapılmasında aşağıdaki parametreler kullanılmıştır:

1. Ulusal ve uluslararası literatürde yer alan, 1994 ile 2016 yılları arasında yayınlanmış rutin olmayan problem çözme değişkenini konu edinen deneysel ve betimsel araştırmalar analiz edilmiştir. Ulaşılan deneysel araştırmalarda, rutin olmayan problem çözmenin bağımlı değişken olarak nitelendirildiği ve bu değişkene çeşitli bağımsız değişkenlerin etkisini belirlemeyi amaç edinen araştırmalar seçilmiştir. Betimsel çalışmalardan ise rutin olmayan problem çözmenin tek değişken olarak incelendiği basit betimsel veya sözü edilen değişkenin çeşitli değişkenlerle ilişkilendirildiği ilişkisel/karşılaştırmalı araştırmalar çalışma kapsamına dahil edilmiştir. Rutin olmayan problemlerle ilgili teorik ve derleme türündeki çalışmalar analiz kapsamına dahil edilmemiştir.

2. Deneysel araştırmalar seçilirken karşılaştırmalı ya da tek gruplu deneysel çalışmalara yer verilmiştir. Deneysel çalışmalarda rutin olmayan soru çözme değişkeni dışında başka bir bağımlı değişkene yer verilmiş ise bu değişken(ler) amaç dışı olması gerekçesiyle analize dahil edilmemiştir. Benzer şekilde betimsel araştırmalarda da bu çalışmanın amacı dışındaki diğer değişkenler analiz sürecine dahil edilmemiştir.

3. Sözü edilen bu amaçlara yönelik ulusal ve uluslararası hakemli dergilerde yayımlanmış makaleler, PDF uzantılı olarak erişilebilen tezler ve bilimsel kongrelerde sunulan ve basılı kitapta yayımlanan bildiriler analiz edilmiştir. Analize, yazım dili Türkçe ya da İngilizce olan araştırmalar dahil edilmiştir.

\section{İ̧̧erik Analizi Yönergesi}


Araştırma örneklemine dahil edilen toplam 60 adet çalışmanın analiz edilmesinde 4 soru kullanılmıştır. Bu soruların her biri araştırmada birer boyut olarak ele alınmıştır. Analiz amacıyla ele alınan sorular aşağıdaki gibidir:

1. Araştırmaların, araştırma yöntemlerine, veri toplama aracı türüne ve örneklem türüne göre dağılımı nasıldır?

2. Çeşitli bağımsız değişkenlerin rutin olmayan problem çözmeye etkisinin belirlendiği deneysel çalışmalarda elde edilen sonuçlar nelerdir?

3. Rutin olmayan problem çözme ile ilgili basit betimsel araştırmalardan elde edilen sonuçlar nelerdir?

4. Rutin olmayan problem çözme ile ilgili ilişkisel/karşılaştırmalı betimsel araştırmalardan elde edilen sonuçlar nelerdir?

\section{Verilerin Kodlanması ve Çözümlenmesi}

Verilerin kodlanması aşamasında öncelikle tüm araştırmalar elektronik dosya biçimine dönüştürülmüş ve ortak bir dosya havuzuna kayıt edilmiştir. Daha sonra Excel dosyasında tüm araştırmaların yazar isimleri listelenerek isimler ve ilgili dosyaları arasında komutsal bağlantı kurulmuştur. $\mathrm{Bu}$ sayede istenilen araştırma metnine kolaylıkla ulaşılması sağlanmıştır. Bu aşamadan sonra her bir araştırmaya bilgisayar dosyasında bir satır atanmıştır. Her bir araştırmanın ait olduğu satırın karşısına her bir soruya ait birer sütun açılmıştır. Her bir soruya ait sütuna kategoriler belirlenmiştir (araştırma türü, örneklem türü, veri toplama aracı, değişkenler, bulgular). Her bir çalışma, ilgili satır ve sütunlarda ait olduğu kategoriye kodlanmıştır.

Araştırmada deneysel çalışmalar bağımlı değişkene etkisi araştırılan bağımsız değişkenlere göre gruplanmıştır. Daha sonra rutin olmayan problem çözmeye etkisi belirlenen belli bir değişkenin kaç değişik çalışmada rapor edildiği frekans türünden sunulmuştur. Basit betimsel araştırmalar analiz edilirken ise rutin olmayan problem çözme ile ilgili çalışılan değişkenler benzer özelliklerine göre genel temalar altında toplanmış. Daha sonra temalar altında araştırmalardan elde edilen genellenmiş bulgu ifadeleri tablolaşstırılmıştır. Deneysel çalışmalarda olduğu gibi belli bir bulgunun kaç değişik çalışmada rapor edildiği frekans türünden sunulmuştur. İlişkisel/karşılaştırmalı çalışmalarda ise ilk olarak rutin olmayan problem çözmeyle ilişkilendirilen değişkenler cinsiyet, matematik başarısı, strateji kullanımı, sınıf düzeyi, görsellik kullanımı, üstbiliş farkındalı̆̆ı, soru türü, problem çözme inancı, özyeterlik algısı, anne-baba rolü, öğretmen grubu, matematiğe yönelik inanç, okul öncesi eğitim alma, zeka düzeyi ve ülkeler başlıkları altında gruplanmıştır. Bu tür araştırmalarda 
rutin olmayan problem çözme değişkenin de ayrıntılı özelliklerine göre çeşitli gruplarda toplanmasına karar verilmiştir. Buna göre kategoriler problem çözme düzeyi, problem çözmede gerçek yaşam bilgisini kullanma, kitapta rutin olmayan probleme yer verme düzeyi ve strateji kullanımıdır. Kategoriler altında yer verilmiş genellenmiş bulgu ifadelerinin kaç değişik çalışmada rapor edildiği frekans türünden sunulmuştur.

Kodlama güvenilirliği sağlamak amacıyla, veriler iki araştırmacı tarafından bağımsız olarak kodlanmıştır. Daha sonra, bütün kodlamalar tek tek incelenmiş ve kodlayıcılar arasında ortaya çıkan uyumsuzluklar tartışılarak ortak bir sonuca varılmıştır.

\section{Verilerin Analizi}

Her bir araştırma öngörülen sorulara dayalı olarak kodlandıktan sonra, kategorilerin kaç kez tekrarlandığı frekans (f) ve yüzde (\%) olarak hesaplanmıştır. Her bir içerik analizi sorusu için elde edilen bütün veriler tablolaştırılmıştır.

\section{Bulgular ve Yorumlar}

$\mathrm{Bu}$ bölümde, araştırma amacına uygun olarak elde edilen bulgular içerik analizi yönergesinde belirtilen dört soruya ilişkin başlıklar altında tablolaştırılarak sunulmuştur.

1. Araştırmaların, araştırma yöntemlerine, veri toplama aracı türüne ve örneklem türüne göre dağılımı nasıldır?

Tablo 1 Araştırmaların Dağılımı

\begin{tabular}{|c|c|c|}
\hline Araştırma Türü & $\mathbf{f}$ & $\%$ \\
\hline Basit Betimsel & 28 & 45.9 \\
\hline Illişkisel & 17 & 27.9 \\
\hline Deneysel & 16 & 26.2 \\
\hline \multicolumn{3}{|l|}{ Örneklem Türü } \\
\hline Ögrenci & 50 & 79.3 \\
\hline Öğretmen Adayı & 6 & 9.5 \\
\hline Ögretmen & 3 & 4.8 \\
\hline Anne-baba & 1 & 1.6 \\
\hline Kitap, ögretim programı, vb. & 3 & 4.8 \\
\hline \multicolumn{3}{|l|}{ Veri Toplama Aracı } \\
\hline Başarı Testi & 54 & 57.4 \\
\hline Ölçek/Anket & 18 & 19.2 \\
\hline Görüşme & 15 & 16 \\
\hline Gözlem & 4 & 4.2 \\
\hline Doküman & 3 & 3.2 \\
\hline
\end{tabular}

Tablo 1'e göre çalışmaların 28'i basit betimsel yöntem (\%45.9), 17'si ilişkisel betimsel yöntem (\%27.9) ve 16's1 deneysel yöntem (\%26.2) ile yürütülmüştür. Tablo 1'de örneklem türüne göre çalışmaların 50'sinin öğrenci (\%79.3), 6'sının öğretmen adayı (\%9.5), 3'ünün öğretmen (\%4.8), 1'inin anne-baba (\%1.6) ve 3'ünün kitap, öğretim programı vb. 
kaynaklarla yürütüldüğü görülmektedir. Son olarak veri toplama aracına göre dağılımın 54'ünü başarı testi (\%57.4), 18'ni ölçek/anket (\%19.2), 15'ini görüşme (\%16), 4'ünü gözlem (\%4.2) ve 3’ünü doküman inceleme (\%3.2) oluşturmaktadır.

2. Çeşitli bağımsız değişkenlerin rutin olmayan problem çözmeye etkisinin belirlendiği deneysel çalışmalarda elde edilen sonuçlar nelerdir?

Tablo 2 Deneysel Çalışmalarda Elde Edilen Sonuçlar

\begin{tabular}{|c|c|c|c|c|}
\hline \multicolumn{2}{|c|}{ Bağımsız Değişken } & \multirow{3}{*}{$\mathbf{f}$} & \multirow{2}{*}{\multicolumn{2}{|c|}{$\begin{array}{l}\text { Rutin Olmayan } \\
\text { Problem Çözme }\end{array}$}} \\
\hline \multirow[t]{2}{*}{ Tema } & \multirow[t]{2}{*}{ Alt Tema } & & & \\
\hline & & & $\begin{array}{c}\text { Olumlu Etki } \\
(\mathbf{f})\end{array}$ & Etki Yok (f) \\
\hline \multirow[t]{2}{*}{ Strateji Eğitimi } & *Problem Çözme Str. & 5 & 5 & - \\
\hline & *Üstbilişsel Strateji & 4 & 3 & 1 \\
\hline \multirow{6}{*}{$\begin{array}{l}\text { Ögretim Yaklaşım } \\
\text { Yöntem ve Teknikleri }\end{array}$} & *Modelleme Yaklaşımı & 2 & 1 & 1 \\
\hline & *Soruluş ve Çözüm Şekli & 2 & 2 & - \\
\hline & *Gruba Dayalı Öğretim & 1 & 1 & - \\
\hline & *Bulmaca ve Oyun & 1 & 1 & - \\
\hline & *Etkinlik Temelli Öğrt. & 1 & 1 & - \\
\hline & TOPLAM & 16 & 14 & 2 \\
\hline
\end{tabular}

Tablo 2'ye bakıldığında incelenen 16 deneysel çalışmanın 5'inde bağımsız değişken olarak "problem çözme stratejisi” 4'ünde "üstbilişsel öğrenme stratejisi”, 2'şer çalışmada "modelleme yaklaşımı" ve "soruların soruluş ve çözüm şeklinin" etkisi araştırılmıştır. Ayrıca birer çalışmada ise "gruba dayalı öğretim", "bulmaca/oyun" ve "etkinlik temelli öğretim" değişkenlerinin etkisinin incelendiği görülmektedir. Tablo 2'ye göre sadece 2 çalışmada incelenen bağımsız değişkenin rutin olmayan problem çözmeye etkisi olmadığı rapor edilmiştir. Bu araştırmalarda sözü edilen bağımsız değişkenler ise "üst bilişsel strateji eğitimi”" ve "modelleme yaklaşımı" dır. Ancak bir başka çalışmada derste "modelleme yaklaşımının" kullanılmasının kullanılmayan duruma kıyasla problem çözmeye daha fazla etki ettiği rapor edilmiştir. Benzer şekilde, “üstbilişsel strateji” kullanımının problem çözmeye etkisi olmadığ1 şeklinde rapor edilen bir çalışmaya kıyasla, 3 çalışmada aksi durum rapor edilmiştir.

3. Rutin olmayan problem çözme ile ilgili basit betimsel araştırmalardan elde edilen sonuçlar nelerdir? 
Tablo 3 Basit Betimsel Çalışmalarda Elde Edilen Sonuçlar

\begin{tabular}{|c|c|c|}
\hline Değişken & Bulgular & $\mathbf{f}$ \\
\hline $\begin{array}{l}\text { Üstbilişsel/ } \\
\text { Özdüzenleme }\end{array}$ & $\begin{array}{l}\text { * Üstbilişsel davranışlar rutin olmayan problemlerde strateji kullanımı için } \\
\text { onemlidir. }\end{array}$ & 1 \\
\hline Stratejileri & $\begin{array}{l}\text { *Öğrenciler rutin olmayan problemleri çözerken özdüzenleme becerilerini } \\
\text { kullanmada güçlük çekmektedir. }\end{array}$ & 1 \\
\hline \multirow[t]{2}{*}{$\begin{array}{l}\text { Problem Çözme } \\
\text { Stratejisi }\end{array}$} & $\begin{array}{l}\text { *Öğgrenciler problemi birden fazla strateji kullanarak çözme konusunda yeterli } \\
\text { değildir. }\end{array}$ & 8 \\
\hline & *öğrenciler rutin olmayan soruları rutinmiş gibi çözme eğilimindedir. & 3 \\
\hline Problem Çözme & $\begin{array}{l}\text { *Üstün yetenekli ögrencilerin rutin olmayan soruları çözmede başarllı oldukları } \\
\text { görülmüşür. }\end{array}$ & 2 \\
\hline Düzeyi & $\begin{array}{l}\text { *Öğretmen adaylarının ya da öğrencilerin rutin sorularda daha başarılı } \\
\text { oldukları görülmüştür. }\end{array}$ & 2 \\
\hline Transfer Becerisi & $\begin{array}{l}\text { *Öğretmen adayları ya da öğrenciler gerçek yaşam bilgisini rutin olmayan } \\
\text { problemlerin çözümüne aktarmakta zorlanmaktadır. }\end{array}$ & 6 \\
\hline İnanç, Tutum, & $\begin{array}{l}\text { *Öğretmenler düşünme becerisini geliştirdiği için rutin olmayan problemleri } \\
\text { faydalı bulmuş, ancak sinavlarda sormak istemediklerini belirtmişlerdir. }\end{array}$ & 1 \\
\hline Motivasyon & $\begin{array}{l}\text { * Öğrenciler ya da öğretmen adayları rutin olmayan sorulara karşı hem olumlu } \\
\text { hem olumsuz görüş̧ bildirirken, çözümde sıkıntı yaşadıklarını belirtmiştir. }\end{array}$ & 3 \\
\hline Problem Türü & $\begin{array}{l}\text { *Matematik ders kitaplarında ya da derslerde daha çok rutin sorulara yer } \\
\text { vermektedir. }\end{array}$ & 3 \\
\hline
\end{tabular}

Tablo 3'de rutin olmayan problem çözmeye yönelik yürütülen basit betimsel çalışmalarda genellenmiş tema ifadelerinin üstbilişsel/özdüzenleme stratejileri, problem çözme stratejisi, problem çözme düzeyi, transfer becerisi, inanç, tutum, motivasyon ve problem türü olduğu görülmektedir. Tabloda tekrar etme sıklığı olarak en çok dikkat çeken tema problem çözme stratejisidir. Bu tema altında yer alan genellenmiş bulgu ifadelerine göre, 8 çalışmada öğrencilerin "problemi birden fazla strateji kullanarak çözme konusunda yeterli olmadıkları" ve 3 çalışmada ise "rutin olmayan soruları rutinmiş gibi çözme eğiliminde" olduklarına yönelik sonuçlar rapor edilmiştir. Diğer dikkat çeken temalardan biri olan transfer becerisiyle ilgili olarak ise 6 araştırmada "öğretmen adayları ya da öğrenciler gerçek yaşam bilgisini rutin olmayan problemlerin çözümüne aktarmakta zorlanmaktadır" bulgusu rapor edilmiştir. Genellenmiş bulgu ifadelerinin bir araya getirilmesi sonucu oraya çıkan temalardan bir diğeri ise "problem çözme düzeyidir". Bu temanın altında yer alan bulgu ifadelerinden birincisinin üstün yetenekli öğrencilerin rutin olmayan soruları çözmede başarılı oldukları, diğerinin ise öğretmen adaylarının ya da öğrencilerin rutin sorularda daha başarılı oldukları şeklindedir. Çalışmada elde edilen “üstbilişsel/özdüzenleme stratejileri” teması altında yer alan bulgu ifadeleri ise üstbilişsel davranışların rutin olmayan problemlerde strateji kullanımı için önemli olduğu ve öğrencilerin rutin olmayan problemleri çözerken özdüzenleme becerilerini kullanmada güçlük çekmeleridir. Çalışmada elde edilen "inanç, tutum, motivasyon" teması altında yer alan bulgu ifadelerine göre ise incelenen araştırmalarda, öğrenciler ya da öğretmen adayları rutin olmayan sorulara karşı hem olumlu 
hem olumsuz görüş bildirmişler; düşünme becerisini geliştirdiği için rutin olmayan problemleri faydalı bulmuşlar, ancak sınavlarda sormak istemediklerini belirtmişlerdir. Son olarak Tablo 3'deki "problem türü” olarak adlandırılan tema altında yer alan genellenmiş bulgu ifadelerine göre, 6 çalışmada Matematik ders kitaplarında ya da derslerde daha çok rutin sorulara yer verildiğine yönelik sonuçlar rapor edilmiştir.

4. Rutin olmayan problem çözme ile ilgili ilişkisel/karşılaştırmalı betimsel araştırmalardan elde edilen sonuçlar nelerdir?

Tablo 4 İlişkisel/Karşılaştırmalı Araştırmalardan Elde Edilen Sonuçlar

\begin{tabular}{|c|c|c|c|}
\hline \multicolumn{4}{|c|}{ İlişkileri Aranan Değişkenler } \\
\hline Değişken 1 & Değişken 2 & $\mathbf{f}$ & Bulgular \\
\hline \multirow{16}{*}{$\begin{array}{l}\text { *Problem Çözme } \\
\text { Düzeyi }\end{array}$} & *Cinsiyet & 2 & *Cinsiyete göre fark yok. \\
\hline & *Matematik Başarısı & 1 & *Pozitif yönde ilişki var. \\
\hline & *Strateji Kullanımı & 2 & $\begin{array}{l}\text { *Her iki çalışmada da ilişki var, ayrıca, } \\
\text { çalışmanın birinde, farklı stratejiler kullanan } \\
\text { ögrencilerin daha basarll olduğu bulunmustur. }\end{array}$ \\
\hline & *Sınıf Düzeyi & 1 & *8. siniflar 6. sinıflardan daha başarılı. \\
\hline & $\begin{array}{l}\text { *Sorularda Görselliğe } \\
\text { Yer Verilmesi }\end{array}$ & 1 & $\begin{array}{l}\text { *Görsellerin kullanılması öğrenci başarısında } \\
\text { fark yaratmamıştır. }\end{array}$ \\
\hline & 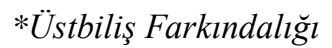 & 1 & *Pozitif yönde ilişki var. \\
\hline & *Soru Türü & 1 & *Öğrenciler rutin sorularda daha başarılı. \\
\hline & *Problem Çözmeye & 1 & *Pozitif yönde ilişki var. \\
\hline & Yönelik İnanç & & \\
\hline & *Özyeterlik Algisl & 1 & *Anlamlı bir ilişki yok. \\
\hline & *Anne-Baba Rolü & 1 & *Pozitif yönde ilişki var. \\
\hline & *Öğretmen Grubu & 1 & $\begin{array}{l}\text { *Öğretmenler ve ögrretmen adayları arasında } \\
\text { fark yok. }\end{array}$ \\
\hline & $\begin{array}{l}\text { *Matematiğe Yönelik } \\
\text { Inanç }\end{array}$ & 1 & *Klsmi ilişkiler var. \\
\hline & $\begin{array}{l}\text { *Okul Öncesi Eğitim } \\
\text { Alıp Almama }\end{array}$ & 1 & *Okul öncesi eğitim alanlar daha başarıll. \\
\hline & *Zeka Düzeyi & 1 & $\begin{array}{l}\text { *Üstün zekalı ögrenciler normal zekalılara göre } \\
\text { strateji kullanımında daha başarılı. }\end{array}$ \\
\hline & $\begin{array}{l}\text { *Ülkelerin } \\
\text { karşılaştırması }\end{array}$ & 1 & $\begin{array}{l}\text { *Çinli öğrencilerin rutin sorularda } \\
\text { Amerikalılardan, Amerikall ögrencilerin de } \\
\text { rutin olmayan sorularda Çinlilerden daha } \\
\text { başarllı olduklarl görülmüşürr. }\end{array}$ \\
\hline \multirow{7}{*}{$\begin{array}{l}\text { *Problem Ç̈̈zmede } \\
\text { Gerçek Yaşam } \\
\text { Bilgisini Kullanma } \\
\text { *Kitapta Rutin } \\
\text { Olmayan Probleme } \\
\text { Yer Verme Düzeyi } \\
\text { *Strateji Kullanımı }\end{array}$} & & 1 & Japon ve Belçikall ögrenciler gerçek yaşam \\
\hline & & & bilgisini kullanmada eşit ölçüde başarısız \\
\hline & & & olmuşlardır. \\
\hline & *Ülkelerin & 1 & Hem Çin hem de ABD'de ders kitaplarındaki \\
\hline & karşılaştırması & & soruların çoğu rutin sorulardır. \\
\hline & & & \\
\hline & & 1 & $\begin{array}{l}\text { Japon ve Amerikalı ögrenciler rutin olmayan } \\
\text { problemleri benzer stratejiler kullanarak } \\
\text { çözmüşler, Japon ögrenciler daha üst düzey } \\
\text { açıklamalar yapmışlardır. }\end{array}$ \\
\hline
\end{tabular}

Tablo 4'de yer alan çalışmalarda temel olarak araştırmacıların "rutin soru çözme düzeyi” ile çeşitli değişkenler arasındaki ilişkileri incelediği görülmektedir. Buna göre soru çözme düzeyi ile ilişkilendirilen sürekli ya da süreksiz değişkenlerin cinsiyet, matematik 
başarısı, strateji kullanımı, sınıf düzeyi, sorularda görselliğe yer verilmesi, üstbiliş farkındalık, soru türü, problem çözmeye yönelik inanç, özyeterlik algısı, anne-baba rolü, öğretmen grubu, matematiğe yönelik inanç, öğrencilerin okul öncesi eğitim alıp almaması ve ülkeler arası karşılaştırmalardır. Soru çözme düzeyi ile arasında anlamlı ilişki bulunan değişkenler matematik başarısı, strateji kullanımı, üstbilişsel farkındalık, problem çözmeye yönelik inanç ve anne-baba rolüdür. Diğer taraftan soru çözme düzeyi ile arasında ilişki bulunamayan değişkenin öz yeterlilik algısı ve kısmi ilişki bulunan değişkenin ise matematiğe yönelik inançtır. Ayrıca, Tablo 4'e göre incelenen bir çalışmada soru çözme düzeyi açısından okul öncesi eğitim alan öğrencilerin almayanlara göre, başka bir çalışmada 8. sınıf öğrencilerin 6 . sınıf öğrencilerine göre ve bir diğer çalışmada ise Amerikalı öğrencilerin Çinlilere göre daha başarılı olduğu belirlenmiştir. Diğer taraftan başka çalışmalarda, soru çözme düzeyi açısından kız ve erkekler arasında, öğretmen ve öğretmen adayları arasında ve sorularda görsellerin kullanılması ile kullanılmaması durumları arasında anlamlı bir fark olmadığı belirlenmiştir. Tablo 4'de soru çözme düzeyini inceleyen araştırmaların yanı sıra, öğrencilerin "soru çözmede gerçek yaşam bilgisini kullanma düzeyi" ve "kitaplarda rutin olmayan soruya yer verme düzeylerinin” ülkelere göre karşılaştırılmasını amaç edinen 2 çalışmanın olduğu görülmektedir. $\mathrm{Bu}$ araştırma sonuçlarının birinde Japon ve Belçikalı öğrenciler arasında gerçek yaşam bilgisini kullanma düzeyi açısından fark bulunamamış, diğer çalışmada ise Çin ve ABD'de ders kitaplarındaki soruların çoğunun rutin sorulardan oluştuğu ve benzer şekilde aralarında fark olmadığı ayrıca, Japon ve Amerikalı öğrenciler rutin olmayan problemleri benzer stratejiler kullanarak çözdükleri rapor edilmiştir.

\section{Sonuç ve Tartışma}

$\mathrm{Bu}$ araştırmayla alan yazında ulaşılan deneysel ve betimsel araştırma bulguları genellenerek bir takım sonuçların ve önerilerin sunulması amaçlanmıştır. $\mathrm{Bu}$ bölümde öncelikle deneysel çalışmalardan, daha sonra ise betimsel çalışmalardan elde edilen sonuçlar tartışılmıştır. İncelenen deneysel araştırmalara dayalı olarak rutin olmayan problem çözme düzeyine olumlu yönde etkisi olduğu belirlenen bağımsız değişkenlerin problem çözme stratejisi, üstbilişsel öğrenme stratejisi, modelleme yaklaşımı, soruların soruluş/çözüm şekilleri, bulmaca/oyun ve etkinlik temelli öğretim değişkenleri olduğu görülmektedir. Rutin olmayan problem çözme düzeyine etki eden değişken olarak en fazla çalışılan ve rapor edilen bağımsız değişkenlerin “problem çözme stratejisi” ve “üstbilişsel öğrenme stratejisi” olduğu söylenebilir. Sözü edilen bu iki değişkenle ilgili olarak öğrencilerin öğrenme stratejisi 
kullanma düzeylerinin artırılmasının rutin olmayan problem çözme düzeyine olumlu katk1 sağladığ1 görülmektedir. Rutin olmayan problem çözmeye yönelik yürütülen araştırmalardan biri olan Altun ve Memnun (2008)'un çalışmasında verilen eğitimin öğrencilerin problemlere bakış açılarını ve güven duygusunu geliştirdiği, sistematik çalışmayı öğrettiği, karmaşık olayların içinde bile bir matematiksel düzen olduğunu fark ettikleri vurgulanmıştır. Diğer çalışmalarda ise stratejileri öğretme amacı ile hazırlanan ortamın bazı stratejilerin öğretiminde etkin olduğu, bazılarında ise olmadığı görülmüş ve strateji türlerinin farklı etkiye sahip olduğuna dikkat çekilmişstir (Arslan ve Altun, 2007; Altun, Memnun ve Yazgan, 2007).

Lee, Yeo ve Hong (2014) ise problem çözme stratejisine ek olarak, üst bilişsel öğrenme stratejisi eğitimi vermenin onları bağımsız problem çözen öğrenciler haline getireceğini vurgulamaktadır. Üst biliş genel olarak düşünme hakkında düşünme faaliyetine veya biliş hakkındaki bilişlere işaret eden bir kavram olarak tanımlanabilir (Karakelle ve Saraç, 2010). Öğrencinin bildiklerini, yapabildiklerini ya da yapamadıklarını tanımlayabilmesinin, kendi düşünme süreçlerini sorgulayabilmesinin ya da kendi kullandığı stratejileri değerlendirebilmesinin problem çözme sürecine olumlu katk1 gösterdiği düşünülmektedir.

Alanyazında ulaşılabilen araştırma sonuçlarına dayalı olarak öğrencilere gerek problem çözme gerek ise üstbiliş öğrenme stratejinin kazandırılmasının rutin olmayan problem çözme düzeyine olumlu katkı sağladığı sonunca varılmıştır (Altun ve Memnun, 2008; Arslan ve Altun, 2007; Altun, Memnun ve Yazgan, 2007; Yazgan ve Bintaş, 2005; Lee, Yeo ve Hong, 2014; Nancarrow, 2004; Verschaffel ve ark., 1999; Pilten, 2008). Diğer taraftan, alan yazında yer alan soruların soruluş şekilleri, bulmaca/oyun ve etkinlik temelli öğretim gibi değişkenleri ile ilgili birer ya da en fazla ikişer araştırmaya ulaşılabilmiştir. Ulaşılabilen araştırma sayısının azlığı nedeniyle ilgili değişkenler konusunda yorum yapmaktan kaçınılmıştır. Bu noktada çeşitli öğretim yaklaşım, yöntem ve tekniklerin rutin olmayan problem çözmeye etkisini belirlemeyi amaç edinecek daha fazla araştırmaya ihtiyaç duyulduğu söylenebilir.

Bu çalışmada incelen deneysel çalışmaların yanı sıra betimsel çalışmalardan elde edilen genellenmiş bulgulara dayalı olarak da birtakım sonuçlara varılmıştır. Buna göre incelenen çalışmalarda tekrar etme sıklığı olarak en çok dikkat çeken temanın yine problem çözme stratejisi olduğu görülmektedir. İlgili araştırmalardan elde edilmiş en genellenmiş sonuçların, öğrencilerin problemi birden fazla strateji kullanarak çözme konusunda yeterli olmadıkları ve rutin olmayan soruları rutinmiş gibi çözme eğiliminde oldukları şeklindedir. Arslan ve Yazgan (2015) bu konuda yaptıkları çalışmada öğrencilerin problem çözerken ilk denemelerinde kullandıkları stratejilerini sonraki denemelerinde nadiren değiştirdiklerini 
gözlemlemiştir. İncelenen çalışmalarda genel olarak öğrencilerin çok az sayıda informal çözümler ürettikleri, alternatif yaklaşımlar ve özgün çözüm yolları üretmede öğrencilerin büyük çoğunluğunun yetersiz kaldığı vurgulanmaktadır (Artut ve Tarım, 2006; Erdogan, 2015; Bayazit, 2013; İncebacak ve Ersoy, 2016; Muir, Beswick ve Williamson, 2008; Chacko, 2004). Deneysel ve betimsel çalışmaların sonuçlarına göre, öğrencilerin rutin olmayan soruları farklı öğrenme stratejileri kullanarak çözmesi başarılarını artırmakta, ancak öğrenciler genelde sınırlı sayıda ve rutin çözüm yolları kullanmalarından ötürü rutin olmayan soruları çözmede başarısız olmaktadır.

Alanyazında araştırmacıların ayrıca "rutin soru çözme düzeyi” ile çeşitli değişkenler arasındaki ilişkileri incelediği görülmektedir. Elde edilen sonuçlara göre, öğrencilerin soru çözme düzeyi ile arasında anlamlı ilişki bulunan değişkenlerin matematik başarısı, strateji kullanımı, üstbilişsel farkındalık, problem çözmeye yönelik inanç ve anne-baba rolüdür. Diğer taraftan, soru çözme düzeyi ile arasında ilişki bulunamayan değişkenin öz yeterlilik algısı ve kısmi ilişki bulunan değişkenin ise matematiğe yönelik inancın olduğu söylenebilir. Ayrıca, soru çözme düzeyi açısından okul öncesi eğitim alan öğrencilerin almayanlara göre, başka bir çalışmada 8. sınıf öğrencilerin 6. sınıf öğrencilerine göre ve bir diğer çalışmada ise Amerikalı öğrencilerin Çinlilere göre daha başarılı olduğu belirlenmiştir. Diğer taraftan başka çalışmalarda, soru çözme düzeyi açısından kız ve erkekler arasında, öğretmen ve öğretmen adayları arasında ve sorularda görsellerin kullanılması ile kullanılmaması durumları arasında anlamlı bir fark olmadığı belirlenmiştir. Ayrıca, bir araştırmada Japon ve Belçikalı öğrenciler arasında gerçek yaşam bilgisini kullanma düzeyi açısından fark bulunamamış, diğer çalışmada ise Çin ve ABD'de ders kitaplarındaki soruların çoğunun rutin sorulardan oluştuğu ve benzer şekilde aralarında fark olmadığı, ayrıca, Japon ve Amerikalı öğrenciler rutin olmayan problemleri benzer stratejiler kullanarak çözdükleri rapor edilmiştir. Yukarıda sözü edilen değişkenlerle ilgili olarak genelde birer ya da ikişer çalışmaya ulaşıldığından genelleme yapmaktan kaçınılmıştır. Bu noktada önümüzdeki dönemlerde rutin olmayan problem çözme ile ilişkisi aranacak değişkenlere yönelik daha fazla araştırma yapılması gerektiği sonucuna varılmıştır.

$\mathrm{Bu}$ araştırmada en genel sonuç olarak, incelenen araştırmalara katılan öğrencilerin genel olarak problemi birden fazla strateji kullanarak çözme konusunda yeterli olmadıkları ve rutin soruları rutin olmayanlara göre daha kolay çözebildikleri görülmüştür. Diğer taraftan, öğrencilere problem çözme ve üst bilişsel öğrenme stratejileri gibi becerilerin kazandırılmasının başarılarını artırabileceği düşünülmektedir. Ayrıca, çeşitli öğretim 
yaklaşım, yöntem ve tekniklerin rutin olmayan problem çözmeye etkisini belirlemeyi amaç edinecek daha fazla araştırmaya ihtiyaç duyduğu söylenebilir. Son olarak, akademik başarı, problem çözmeye yönelik inanç, öz yeterlilik algısı gibi çeşitli değişkenler ile rutin olmayan problem çözme düzeyi arasında olası ilişkileri belirleyecek daha fazla araştırmaya da ihtiyaç duyulduğu söylenebilir.

\section{Kaynakça}

Altun, M., \& Memnun, D. S. (2008). Mathematics teacher trainees' skills and opinions on solving non-routine mathematical problems. Journal of Theory and Practice in Education, 4(2), 213-238.

Altun, M., Memnun, D. S., \& Yazgan, Y. (2007). Primary school teacher trainees' skills and opinions on solving non-routine mathematical problems. Elementary Education Online, 6(1), 127-143.

Arslan, Ç., \& Altun, M. (2007). Learning to solve non-routine mathematical problems. Illkögretim Online, 6(1).

Arslan, C., \& Yazgan, Y. (2015). Common and flexible use of mathematical non routine problem solving strategies. American Journal of Educational Research, 3(12), 15191523.

Artut, P. D., \& Tarım, K. (2006). İlköğretim öğrencilerinin rutin olmayan sözel problemleri çözme düzeylerinin çözüm stratejilerinin ve hata türlerinin incelenmesi. Çukurova Üniversitesi Sosyal Bilimler Enstitüsü Dergisi, 15(2), 39-50.

Artut, P., \& Tarım, K. (2009). Öğretmen adaylarının rutin olmayan sözel problemleri çözme süreçlerinin incelenmesi. Uludağ Üniversitesi Eğitim Fakültesi Dergisi, 22(1), 53-70.

Asman, D., \& Markovits, Z. (2009). Elementary school teachers' knowledge and beliefs regarding non-routine problems. Asia Pacific Journal of Education, 29(2), 229-249.

Bayazit, İ. (2013). İlköğretim 7. ve 8. sınıf öğrencilerinin gerçek-yaşam problemlerini çözerken sergiledikleri yaklaşımlar ve kullandıkları strateji ve modellerin incelenmesi. Kuram ve Uygulamada Ĕgitim Bilimleri, 13(3), 1903-1927.

Callejo, M. L., \& Vila, A. (2009). Approach to mathematical problem solving and students' belief systems: two case studies. Educational Studies in Mathematics, 72(1), 111-126.

Çelebioglu, B., Yazgan, Y., \& Ezentaş, R. (2010). Usage of non-routine problem solving strategies at first grade level. Procedia-Social and Behavioral Sciences, 2(2), 29682974. 
Chacko, I. (2004). Solution of real-world and standard problems by primary and secondary school students: A Zimbabwean example. African Journal of Research in Mathematics, Science and Technology Education, 8(2), 91-103.

Çelik, D., \& Güler, M. (2013). İlköğretim 6. sınıf öğrencilerinin gerçek yaşam problemlerini çözme becerilerinin incelenmesi. Dicle Üniversitesi Ziya Gökalp Eğitim Fakültesi Dergisi, 20, 180-195.

De Hoyos, M., Gray, E., \& Simpson, A. (2004). Uncertainty during the early stages of problem solving. Proceedings of the 28th Conference of the International, 2, 255-262.

Dündar, S. (2015). Öğretmen adaylarının seriler konusuyla ilgili alıştırmaları ve rutin olmayan problemleri çözme becerilerinin incelenmesi. Kastamonu Ĕ̆itim Dergisi, 23(3), 1293-1310.

Ebret, A. (2015). Etkinlik Temelli Matematik Öğretiminin 3. Stnıf Öğrencilerinin Problem Çözme Becerilerine ve Matematiğe İlişkin Tutumlarına Etkisi. Yayımlanmamış yüksek lisans tezi. Necmettin Erbakan Üniversitesi, Eğitim Bilimleri Enstitüsü.

Elia, I., van den Heuvel-Panhuizen, M., \& Kolovou, A. (2009). Exploring strategy use and strategy flexibility in non-routine problem solving by primary school high achievers in mathematics. ZDM, 41(5), 605.

English, L. D., \& Halford, G. S. (1995). Mathematics education: Models and processes. Mahwah, NJ: Lawrence Erlbaum.

Erdoğan, A. (2015). Turkish primary school studentse strategies in solving a non-routine mathematical problem and some implications for the curriculum design and implementation. International Journal for Mathematics Teaching and Learning, 1-27.

Harskamp, E., \& Suhre, C. (2007). Schoenfeld's problem solving theory in a student controlled learning environment. Computers \& Education, 49(3), 822-839.

İncebacak, B. B., \& Ersoy, E. (2016). Problem solving skills of secondary school students. China-USA Business Review, 15(6), 275-285.

Jurdak, M. (2005). Contrasting perspectives and performance of high school students on problem solving in real world situated, and school contexts. Educational Studies in Mathematics, 63, 283-301.

Karakelle, S., \& Saraç, S. (2010). Üst biliş hakkında bir gözden geçirme: Üstbiliş çalışmaları mı yoksa üst bilişsel yaklaşım mı. Türk Psikoloji Yazıları, 13(26), 45-60.

Kaya, S., Kablan, Z., \& Rice, D. (2014). Examining question type and the timing of IRE pattern in elementary science classrooms. Journal of Human Sciences, 11(1), 621-641. 
Kolovou, A.; van den Heuvel-Panhuizen, M. \& Bakker, A. (2009). Non-routine problem solving tasks in primary school mathematics textbooks - A needle in a haystack. Mediterranean Journal for Research in Mathematics Education, 8(2), 31-68.

Kurbal, M. S. (2015). An Investigation of Sixth Grade Students' Problem Solving Strategies and Underlying Reasoning in the Context of a Course on General Puzzles and Games. Unpublished master's thesis. Middle East Teachnical University.

Lee, N. H., Yeo, D. J. S., \& Hong, S. E. (2014). A metacognitive-based instruction for Primary Four students to approach non-routine mathematical word problems. ZDM, 46(3), 465-480.

Marchis, I. (2012). Non-routine problems in primary mathematics workbooks from Romania. Acta Didactica Napocensia, 5(3), 49-56.

Muir, T., Beswick, K., \& Williamson, J. (2008). "I'm not very good at solving problems": An exploration of students' problem solving behaviours. The Journal of Mathematical Behavior, 27(3), 228-241.

Mullis, I. V., Martin, M. O., Smith, T. A., Garden, R. A., Gregory, K. D., Gonzalez, E. J., ... \& O'Connor, K. M. (2003). TIMSS Trends in mathematics and science study: Assessment frameworks and specifications 2003. International Association for the Evaluation of Educational Achievement.

Nancarrow, M. (2004). Exploration of metacognition and non-routine problem based mathematics instruction on undergraduate student problem-solving success (Unpublished doctoral thesis). The Florida State University, Florida.

Organisation for Economic Co-operation and Development (OECD). (2014). PISA 2012 results: creative problem solving: students' skills in tackling real-life problems (volume $V)$. OECD, Paris, France.

Özmen, Z. M., Taşkın, D., \& Güven, B. (2012). İlköğretim 7. sınıf matematik öğretmenlerinin kullandıkları problem türlerinin belirlenmesi. Eğitim ve Bilim, 37(165), 246-261.

Pantziara, M., Gagatsis, A., \& Elia, I. (2009). Using diagrams as tools for the solution of nonroutine mathematical problems. Educational Studies in Mathematics, 72(1), 39-60.

Pilten, P. (2008). Üstbiliş stratejileri öğretiminin ilköğretim beşinci sınıf öğrencilerinin matematiksel muhakeme becerilerine etkisi. Yayınlanmamış Doktora Tezi, Gazi Üniversitesi, Eğitim Bilimleri Enstitüsü, Ankara.

Polya, G. (1962). Mathematical discovery: On understanding, learning, and teaching problem solving. New York, NY: John Wiley \& Sons. 
Pourdavood, R. R. (2012). Classrooms socio-mathematical discourse: two nine-grade-dyads' non-routine problem-solving engagement. American Journal of Human Ecology, 1(2), 44-50.

Santos-Trigo, M., \& Camacho-Machín, M. (2009). Towards the construction of a framework to deal with routine problems to foster mathematical inquiry. Primus, 19(3), 260-279.

Schoenfeld, A. H., (1999). Looking toward the 21st century: Challenges of educational theory and practice. Educational Researcher, 28(7), 4-14.

Silver, E. A., Ghousseini, H., Gosen, D., Charalambous, C. \& Strawhun, B. T. F. (2005) Moving from rhetoric to praxis: Issues faced by teachers in having students consider multiple solutions for problems in the mathematics classroom. Journal of Mathematical Behavior, 24, 287-301.

Stein, M. K., Grover, B. W., \& Henningsen, M. (1996). Building students' capacity for mathematical thinking and reasoning: An analysis of mathematical tasks used in reform classrooms. American Educational Research Journal, 33(2), 455-488.

Taşkın, D., Aydın, F., Akşan, E., \& Güven, B. (2012). Ortaöğretim öğrencilerinin problem çözmeye yönelik inanç ve öz-yeterlilik algıları ile rutin ve rutin olmayan problemlerdeki başarıları arasındaki ilişkinin incelenmesi. e-Journal of New World Sciences Academy, $7(1)$.

Taylor, J. A., \& McDonald, C. (2007). Writing in groups as a tool for non-routine problem solving in first year university mathematics. International Journal of Mathematical Education in Science and Technology, 38(5), 639-655.

Teong, S. K., Hedberg, J. G., Ho, K. F., Lioe, L. T., Tiong, Y. S. J., Wong, K. Y. \& Fang, Y. P. (2009). Developing the repertoire of heuristics for mathematical problem solving: Project 1. Final Technical Report for Project CRP1/04 JH. Singapore: Centre for Research in Pedagogy and Practice, National Institute of Education, Nanyang Technological University.

Ulu, M. (2008). Sınıf öğretmeni-sınıf ögrretmeni adayı ve 5. Sinıf ögrencilerinin dört işlem problemlerini çözmede kullandıkları stratejilerin karşılaştırılması. Afyon Kocatepe Üniversitesi, Yayınlanmamış yüksek lisans tezi.

Van Streum, A. (2000). Representations in applying functions. International Journal of Mathematics in Science and Technology, 31(5), 703-725. 
Verschaffel, L., \& De Corte, E. (1997). Teaching realistic mathematical modeling in the elementary school: A teaching experiment with fifth graders. Journal for Research in mathematics education, 577-601.

Verschaffel, L., De Corte, E., Lasure, S., Van Vaerenbergh, G., Bogaerts, H., \& Ratinckx, E. (1999). Learning to solve mathematical application problems: A design experiment with fifth graders. Mathematical thinking and learning, 1(3), 195-229.

Yazgan, Y., \& Bintaş, J. (2005). İlköğretim dördüncü ve beşinci sınıf öğrencilerinin problem çözme stratejilerini kullanabilme düzeyleri: Bir öğretim deneyi. Hacettepe Üniversitesi Eğitim Fakültesi Dergisi, 28, 210-218.

Yıldırım, S., \& Ersözlü, Z. N. (2013). The relationship between students' metacognitive awareness and their solutions to similar types of mathematical problems. Eurasia Journal of Mathematics, Science \& Technology Education, 9(4), 411-415.

Yıldırım, A., \& Şimşek, H. (2005). Sosyal bilimlerde nitel araştırma yöntemleri. Ankara: Seçkin Yayıncılık. 